\title{
Electro-Acupuncture Promotes Endogenous Multipotential Mesenchymal Stem Cell Mobilization into the Peripheral Blood
}

\author{
Lizhen Liu ${ }^{\mathrm{a}}$ Qin $\mathrm{Yu}^{\mathrm{b}}$ Kaimin $\mathrm{Hu}^{\mathrm{a}}$ Binsheng Wang ${ }^{\mathrm{a}}$ Yiran Zhang ${ }^{\mathrm{a}}$ Yulin $\mathrm{Xu}^{\mathrm{a}}$ \\ Shan Fu ${ }^{a}$ Xiaohong Yu ${ }^{a}$ He Huanga \\ aBone Marrow Transplantation Center, The First Affiliated Hospital, Zhejiang University School of \\ Medicine, Hangzhou, ${ }^{b}$ College of Life Science, Zhejiang Chinese Medical University, Hangzhou, China
}

\section{Key Words}

Electro-acupuncture $\bullet$ Mesenchymal stem cells $\bullet$ Mobilization $\bullet$ Peripheral blood $\bullet$ Differentiation - Stromal cell-derived factor-1 $\alpha$

\begin{abstract}
Background/Aims: Mobilization of endogenous stem cells is an appealing strategy for cell therapy. However, there is little evidence for reproducible, effective methods of mesenchymal stem cell (MSC) mobilization. In the present study, we investigated the mobilizing effect of electro-acupuncture (EA) on endogenous MSCs. Methods: Normal adult rats were randomly divided into six groups, namely, EA for 14 days (EA14d), sham EA14d, EA21d, sham EA21d and matched control groups. MSC mobilization efficiency was determined by colony-forming unit fibroblast (CFU-F) assays. Mobilized peripheral blood (PB)-derived MSCs were identified by immunophenotype and multi-lineage differentiation potential. Results: CFU-F frequency was significantly increased in the PB of EA14d rats compared with the sham EA and control groups. Moreover, the number of CFU-Fs was increased further in the EA21d group. MSCs derived from EA-mobilized PB were positive for CD90 and CD44, but negative for CD45. Additionally, these cells could differentiate into adipocytes, osteoblasts, chondrocytes and neural-like cells in vitro. Finally, stromal cell-derived factor-1 $\alpha$ (SDF-1 $\alpha$ ) was increased in the PB of rats subjected to EA, and the migration of MSCs was improved in response to SDF-1 $\alpha$. Conclusions: MSCs with multi-lineage differentiation potential can be mobilized by EA. Our data provide a promising strategy for MSC mobilization.

\section{Introduction}

Mesenchymal stem cells (MSCs) are a population of non-haematopoietic stromal cells with the potential for extensive self-renewal and multi-lineage differentiation, presenting exciting possibilities for cellular therapy [1-3]. In addition to their ability to differentiate into L. Liu and Q. Yu contributed equally to this work.




\section{Cellular Physiology Cell Physiol Biochem 2016;38:1605-1617 \\ \begin{tabular}{ll|l} 
and Biochemistry & Dublished online: April 18, 2016 & $\begin{array}{l}\text { ○ 2016 The Author(s). Published by S. Karger AG, Basel } \\
\text { www.karger.com/cpb }\end{array}$ \\
\hline
\end{tabular}}

Liu et al.: Electro-Acupuncture Promotes MSC Mobilization into the PB

osteoblasts, chondroblasts and adipocytes, it has also been suggested that bone marrowderived MSCs can differentiate into cells of neuronal and glial lineages [4, 5]. MSCs possess unique characteristics that make them attractive therapeutic candidates for tissue repair and disease treatment [6-8].

Mobilization of endogenous stem and progenitor cells is an appealing strategy for cell therapy. Mobilized cells home to the site of injury and take part in tissue regeneration, thereby circumventing these issues [9-12]. This approach has been established clinically using granulocyte colony-stimulating factor (G-CSF) to mobilize haematopoietic stem cells for bone marrow transplantation [13]. A similar approach has also been used for mobilizing endothelial progenitor cells for the treatment of myocardial infarction and limb ischaemia $[12,14]$. The mobilization of MSCs is similarly appealing, but there is little evidence for reproducible, effective methods that promote their mobilization [9-11].

Circulating MSCs have been previously identified only at very low frequencies [15]. However, emerging evidence suggests that a small number of MSCs can potentially be mobilized into the circulation in response to specific stimuli, such as acute burn [16], fracture [17] and hypoxia [18, 19]. Recently, Moldenhauer et al. [20] found that acupuncture in healthy human individuals induced the mobilization of $\mathrm{CD} 133^{+} \mathrm{CD} 34$ cells, a population of neurogenic stem cells. In addition, Chen and colleagues reported that electro-acupuncture (EA) improved survival and migration of transplanted neural stem cells in injured rat spinal cord [21]. Another study further showed that the survival and differentiation of transplanted MSCs were promoted by EA treatment [22]. We therefore hypothesized that acupuncture or EA might be an effective stimulus to induce the release of endogenous MSCs into the blood.

Acupuncture, a traditional oriental medicine practiced for more than 2500 years, is becoming more popular worldwide. Notably, acupuncture has been recommended by the World Health Organization (WHO) as an effective complementary therapy for numerous diseases [23]. EA is based on conventional acupuncture, with the additional application of an electric pulse to acupoints to strengthen the acupuncture. Because its parameters are easily controlled and stimulation models are correspondingly stable, EA is widely used for both basic research and clinical therapy. Thus, in this study, we investigated the mobilizing effect of EA on endogenous MSCs.

In Traditional Chinese Medicine, Governor Vessel (GV) acupoints master the "Yang Qi" of the body, which has also been called "the sea of Yang Meridians." EA on GV acupoints has been used widely in the clinic. Increasing evidence suggests that GV-EA promotes migration and differentiation of endogenous neurogenic stem cells [21, 22, 24]. Hence, we chose Jizhong (GV6) and Mingmen (GV4), one pair of "Governor Vessel" acupoints, to investigate the MSC-mobilizing effect of EA.

\section{Materials and Methods}

Animals

Sixty adult male Sprague-Dawley rats (6 weeks, 200 - 220 g) were provided by the Experimental Animal Center of Zhejiang University. They were randomly divided into six groups, namely, EA for 14 days (EA14d), sham point EA for 14 days (Sham14d), control (immobilization without needle insertion or electrical stimulation) for 14 days (Con14d), EA21d, Sham21d and Con21d ( $\mathrm{n}=10$ per group). Animals were housed under controlled conditions of light and temperature with ad libitum access to water and food. All animal investigations were performed in accordance with the Guide for the Care and Use of Laboratory Animals published by the NIH and were approved by the Institutional Animal Care and Use Committee of Zhejiang University.

Electro-acupuncture stimulation

EA was administered according to the practices of Traditional Chinese Medicine. One pair of "Governor Vessel" acupoints, Jizhong (GV6) and Mingmen (GV4) (Fig. 1A), was utilized during EA treatment. Localization of these acupoints was based on available rodent acupoint charts and on anatomical references, 


\section{Cellular Physiology Cell Physiol Biochem 2016;38:1605-1617

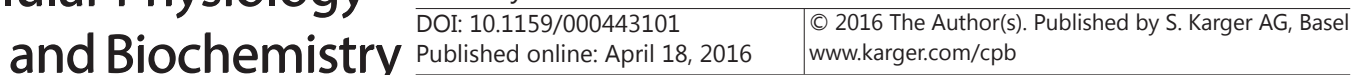

A

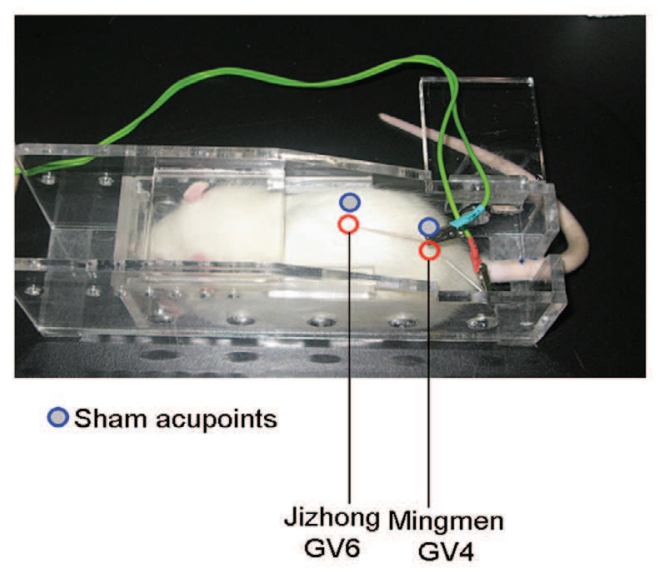

B

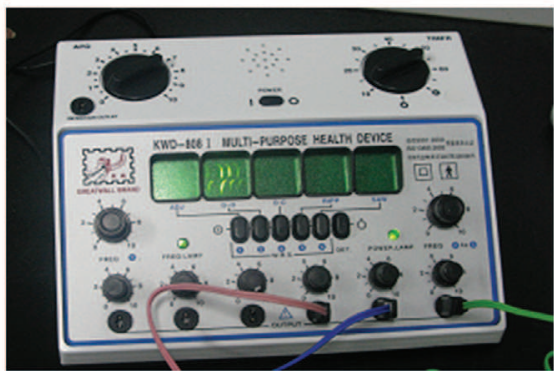

c

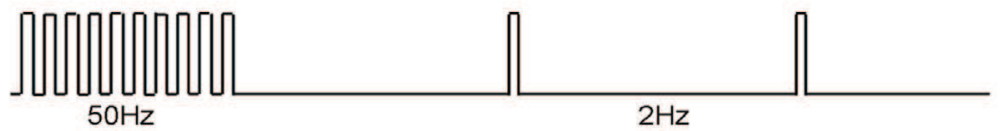

Fig. 1. Immobilization and electro-acupuncture (EA) apparatus. (A) Photograph showing an immobilization apparatus for EA treatment without anaesthesia, and the locations of acupoints. Red circles show the locations of Jizhong (GV6) and Mingmen (GV4). Blue circles show the locations of sham acupoints. (B) Photograph showing the EA apparatus used in the present study. (C) Schematic diagram showing the dense-sparse waveforms of the EA apparatus.

such as bones and joints. The acupoint GV6 is located on the posterior midline in the depression below the spinous process of the eleventh thoracic vertebra in the prone position. GV4 is located on the posterior midline in the depression below the spinous process of the second lumbar vertebra in the prone position. The exact location of the selected acupoints was confirmed using an EA apparatus that emits a sound signal under low electrical resistance and high conductance.

EA treatment was applied to the rats once per day for 14 days (EA14d group) or 21 days (EA21d group) without anaesthesia using an immobilization apparatus that allowed access to both acupoints (Fig. 1A). Stainless silver needles of $0.3 \mathrm{~mm}$ in diameter were inserted into each acupoint at a depth of approximately $5 \mathrm{~mm}$. The minimum voltage to cause moderate muscle contraction was used for stimulation. The two needles were connected to the output terminals of an EA apparatus (Model KWD-808, Changzhou Medical Electronic Apparatus Company, China) (Fig. 1B). EA stimulation was applied for $30 \mathrm{~min}$ with an electrical current of faradic, bipolar and dense-sparse frequencies ( $50 \mathrm{~Hz}$ for $1.05 \mathrm{~s}$ and $2 \mathrm{~Hz}$ for $2.85 \mathrm{~s}$, Fig. 1C).

Two sham acupoints (non-acupuncture points) were utilized in the sham EA group. The sham points were located at the dermatome immediately next to the Jizhong (GV6) and Mingmen (GV4) acupoints in areas where the sound signal was absent (Fig. 1A). Sliver needles were inserted into each sham acupoint at a depth of less than $2 \mathrm{~mm}$. The handles of the needles were connected to the EA apparatus in the absence of electrical stimulation for 30 minutes, mimicking a real EA procedure. In parallel with the EA groups, sham EA treatment was applied to rats once per day for 14 days (Sham14d group) or 21 days (Sham21d group) (Fig. 1A).

Matched control groups underwent immobilization without needle insertion or electrical stimulation for 14 days (Con14d) or 21 days (Con21d).

\section{Bone marrow and peripheral blood cell preparation}

Immediately after the last acupuncture procedure, animals were anesthetized with $4 \%$ chloral hydrate $(500 \mathrm{mg} / \mathrm{kg}$, Sigma). Peripheral blood (PB) $(8-10 \mathrm{ml})$ was drawn from the postcaval vein and collected in heparinized tubes. Bone marrow (BM) was obtained from the rat femur and tibia as previously described [19]. Briefly, muscles and the connective tissue were detached, and the epiphyses were 


\section{Cellular Physiology Cell Physiol Biochem 2016;38:1605-1617 \begin{tabular}{ll|l} 
and Biochemistry Published online: April 18, 2016 & $\begin{array}{l}\text { ○ 2016 The Author(s). Published by S. Karger AG, Basel } \\
\text { www.karger.com/cpb }\end{array}$ \\
\hline
\end{tabular}}

Liu et al.: Electro-Acupuncture Promotes MSC Mobilization into the PB

removed. Marrow was harvested by inserting an 18-gauge syringe needle into one end of the bone shaft and flushing the contents into a 60-mm culture dish containing Dulbecco's Modified Eagle Medium, low glucose (LG-DMEM) (Invitrogen, Carlsbad, CA) supplemented with 20\% (vol/vol) screened foetal bovine serum (FBS) (Invitrogen). A single-cell suspension was obtained by passing the marrow through needles of decreasing sizes. Peripheral blood- and bone marrow-derived mononuclear cells (MNCs) were separated by Lymphoprep (Haoyang Biological Manufacture Co. Ltd, Tianjin, China).

\section{Colony-forming unit fibroblast ( $C F U$-F) assay}

For CFU-F assays, PB MNCs from each animal were plated at a density of $3 \times 10^{6}$ cells per 35-mm culture dish in proliferation culture medium consisting of LG-DMEM supplemented with 20\% (vol/vol) screened FBS. BM MNCs were plated at a density of $1 \times 10^{6}$ cells per 35 -mm culture dish using the same proliferation culture medium. The culture medium was changed on day 5 , and adherent colonies ( $>50$ cells) derived from CFU-Fs were counted on day 10 for PB-derived cells, and on day 14 for BM-derived cells. To visualize representative colonies, half of the dishes in each group were fixed and stained with $0.5 \%$ crystal violet. Colonies were counted and presented as the average colony number from ten parallel dishes.

\section{Generation and culture of MSCS}

MSCs derived from Con14d BM CFU-Fs and EA14d PB CFU-Fs were trypsinized (0.25\% trypsin-EDTA, Invitrogen) and resuspended in culture medium, consisting of LG-DMEM supplemented with 20\% (vol/vol) FBS. Cells were seeded at a density of 10,000 cells $/ \mathrm{cm}^{2}$ and defined as passage 1 . The culture medium was subsequently replaced every 3 days. Cells used in subsequent experiments were defined as passage 3 (P3).

\section{Flow cytometry assay}

Membrane antigen expression on MSCs derived from mobilized PB of EA14d (EA-PB) and bone marrow of Con14d (Con-BM) rats was determined at P3 by flow cytometry using a FACS Calibur system (Beckman Coulter FC500). A total of $5 \times 10^{5}$ cells from single-cell suspensions were incubated for 30 minutes at room temperature with direct phycoerythrin- or fluorescein isothiocyanate-conjugated mouse anti-rat monoclonal antibodies recognizing CD44, CD73, CD90 and CD45 (BD Bioscience, San Jose, CA). Isotypematched antibodies served as negative controls. After washing and re-suspending in PBS, samples were analysed by collecting 10,000 events using Cell-Quest software (Beckman Coulter).

\section{Differentiation assays}

The differentiation potentials of MSCs derived from EA-PB and Con-BM (P3) were evaluated as follows:

Adipogenesis. Cells were seeded into 6-well plates at 20,000 cells $/ \mathrm{cm}^{2}$ and cultured in proliferation medium consisting of LG-DMEM supplemented with 20\% FBS until confluence. The medium was then replaced with adipogenic induction medium consisting of LG-DMEM with 1×adipogenic stimulatory supplement (Stem Cell Technologies, Hangzhou, China). Cells were cultured for 21 days, and medium was changed every 3 days. Adipogenic differentiation was indicated by cellular accumulation of large lipid vacuoles that stained with oil red 0 (Sigma-Aldrich).

Osteogenesis. Cells were seeded into 6-well plates at 10,000 cells $/ \mathrm{cm}^{2}$ in proliferation medium. After 2 days, the medium was changed to osteogenic induction medium consisting of LG-DMEM with 10\% FBS, 0.1 $\mu \mathrm{M}$ dexamethasone (Sigma-Aldrich), $10 \mathrm{mM} \beta$-glycerophosphate (Sigma-Aldrich) and $50 \mu \mathrm{M}$ ascorbic acid (Sigma-Aldrich). Cells were cultured for 14 days, and the medium was changed every 3 days. Mineralized areas were revealed by von Kossa stain.

Chondrogenesis. Cells at $80 \%$ confluence were trypsinized with $0.25 \%$ (vol/vol) trypsin-EDTA, washed in PBS, and resuspended in high-glucose DMEM containing $0.1 \mu \mathrm{M}$ dexamethasone (Sigma-Aldrich), $1 \mathrm{mM}$ sodium pyruvate (Invitrogen), 1× insulin-transferrin-selenium (Invitrogen), $200 \mu \mathrm{M}$ ascorbic acid (SigmaAldrich), $10 \mathrm{ng} / \mathrm{ml}$ transforming growth factor-1 (Peprotech, London, UK), and $10 \mathrm{ng} / \mathrm{ml}$ transforming growth factor-3 (Peprotech). Viable cells were counted and seeded at a density of $5 \times 10^{5}$ cells per pellet in $15-\mathrm{ml}$ conical tubes. Cells were gently centrifuged to the bottom of the tubes and allowed to form compact cell pellets, which were then incubated in a humidified atmosphere at $37^{\circ} \mathrm{C}$ with $5 \% \mathrm{CO}_{2}$ with medium changes every 3 days. Pellets were embedded in paraffin after 21 days in culture. Cartilage glycosaminoglycans were detected by staining with Toluidine Blue (Sigma-Aldrich). 


\section{Cellular Physiology Cell Physiol Biochem 2016;38:1605-1617 \begin{tabular}{ll|l} 
and Biochemistry Published online: April 18, 2016 & $\begin{array}{l}\text { ○ 2016 The Author(s). Published by S. Karger AG, Basel } \\
\text { www.karger.com/cpb }\end{array}$ \\
\hline
\end{tabular}}

Liu et al.: Electro-Acupuncture Promotes MSC Mobilization into the PB

Neuronal Differentiation of EA-PB-derived MSCS

To induce neuronal differentiation, EA-PB-derived MSCs were grown in DMEM containing 1\% FBS and supplementary $100 \mathrm{ng} / \mathrm{mL}$ basic fibroblast growth factor (bFGF, Peprotech) for seven days. Cells were then incubated in the presence of $10 \mu \mathrm{M}$ forskolin (Sigma) over the next seven days and were subjected to immunocytochemical and RT-PCR analyses.

\section{RT-PCR assay}

The expression of neuronal markers, including neuron-specific enolase (NSE), Nestin, Tuj-1, microtubule-associated protein 2 (MAP2) and glial fibrillary acidic protein (GFAP), were detected by RTPCR. Total cellular RNA was extracted using Trizol reagent (Invitrogen) according to the manufacturer's protocol. Total RNA (1 $\mu \mathrm{g}$ ) was used for cDNA synthesis using the PrimeScript ${ }^{\mathrm{TM}}$ RT-PCR Kit (Takara). The PCR was carried out in a $25 \mu \mathrm{l}$ reaction volume. Each cycle consisted of a denaturation step at $94^{\circ} \mathrm{C}$ for 30 sec, an annealing step at appropriate annealing temperature for $30 \mathrm{sec}$, and an extension step at $72^{\circ} \mathrm{C}$ for $1 \mathrm{~min}$. The final extension step was followed by a $7 \mathrm{~min}$ extension reaction at $72^{\circ} \mathrm{C}$. Primer sequences are listed as follows: NSE: F: CCC TCT ATC GCC ACA TTG CTC R: AAG GGT CAG CGG GAG ACT TGA; Nestin: F: GGA GCC ATT GTG GTC TAC TGA R: GAT GCA ACT CTG CCT TATCC; Tuj1 F: ATC AGT GAC GAG CAT GGC ATAG R: ACA GGG TGG CGT TGT AGGG; MAP2 F: AAC AGA AAC CTA CGA CGAT R: CCT GTC TCC TGA TACGC; GFAP F: GCA GAG ATG ATG GAG CTC AAT GACC R: GTT TCA TCC TGG AGC TTC TGC CTCA; GAPDH F: ACC ACA GTC CAT GCC ATCAC R: TCC ACC ACC CTG TTG CTGTA. Amplified fragments were separated by $1 \%$ agarose gel electrophoresis. Images of the RT-PCR stained with ethidium bromide were analysed with a Gel-PRO Analyzer (Bio-Rad). The density of the bands was quantified using Image J software (National Institutes of Health), and the band intensities of the genes of interest were normalized to GAPDH.

\section{Immunofluorescence assay}

For immunofluorescent analysis, cells were first fixed with 4\% paraformaldehyde for 20 min and washed with PBS. Next, the cells were incubated with $0.2 \%$ Triton-100 for 5 min. Nonspecific binding was blocked by incubation with PBS containing 10\% normal goat serum at room temperature for $1 \mathrm{~h}$. After removing excess serum, the slides were incubated overnight at $4^{\circ} \mathrm{C}$ with a mouse monoclonal antibody against nestin (1:500, R\&D). After washes with PBS, cells were incubated with FITC conjugated goat anti-rabbit secondary antibodies in the dark for $30 \mathrm{~min}$. Nuclei were stained with DAPI (Boster). After washing the slides, immunofluorescence was detected using a fluorescent microscope (Nikon, Japan).

Enzyme-linked immunosorbent assay (ELISA)

The PB plasma levels of vascular endothelial growth factor (VEGF) and stromal cell-derived factor- $1 \alpha$ (SDF-1 $\alpha$ ) were evaluated by ELISA using commercially available kits (Lengton Bioscience Co. Ltd, Shanghai, China) according to the manufacturer's instructions. The analytical sensitivities of the SDF- $1 \alpha$ and VEGF kits were $1.0 \mathrm{pg} / \mathrm{ml}$ and $1.0 \mathrm{ng} / \mathrm{ml}$, respectively.

\section{Cell migration assay}

Cell migration assays were performed in transwell chambers (Greiner, Frickenhausen, Germany). MSCs derived from bone marrow $\left(1 \times 10^{4}\right.$ cells) resuspended in $150 \mu$ of basic medium with $2 \%$ FBS were added to the upper chamber, and $600 \mu \mathrm{l}$ of migration medium with $150 \mathrm{ng} / \mathrm{ml} \mathrm{SDF-1} \alpha$ or basic medium with $2 \%$ FBS was added to the bottom chamber. After a $15 \mathrm{~h}$ incubation at $37^{\circ} \mathrm{C}$, the upper sides of the filters were carefully washed with cold PBS, and cells remaining on the upper face of the filters were removed with a cotton wool swab. Transwell filters were fixed with $4 \%$ paraformaldehyde and stained with crystal violet solution (Sigma-Aldrich). Cells migrating into the lower compartment were counted manually in three random microscopic fields $(\times 200)$ by three independent, blinded investigators.

\section{Statistical analysis}

All data are presented as the mean \pm SEM. Differences between group means were assessed by analysis of variance with multiple comparisons using SPSS 16.0. A p-value of $<0.05$ was considered significant. 


\section{Cellular Physiology \\ Cell Physiol Biochem 2016;38:1605-1617 \\ \begin{tabular}{l|l}
\hline DOI: 10.1159/000443101 & (c) 2016 The Author(s). Published by S. Karger AG, Base
\end{tabular} and Biochemistry

Fig. 2. EA promotes the mobilization of endogenous mesenchymal stem cells (MSCs) into the peripheral blood (PB). (A) A greater number of colonies were observed in the $\mathrm{PB}$ of EA14d and EA21d compared to sham EA (Sham) and control (Con) groups. (B) CFU-F frequency in the PB. The number of CFU-Fs (mean \pmSEM) per $3 \times 10^{6}$ mononuclear cells (MNCs) from the PB of Con, Sham and EA groups ( $\mathrm{n}=10$ per group). ${ }^{* *} p<0.01$ vs. matched control group; $* p<0.05$. C. CFU-F frequency in the $\mathrm{BM}$. The number of CFU-Fs (mean \pm SEM) per $1 \times 10^{6}$ MNCs from the BM of each group ( $\mathrm{n}=10$ per group).

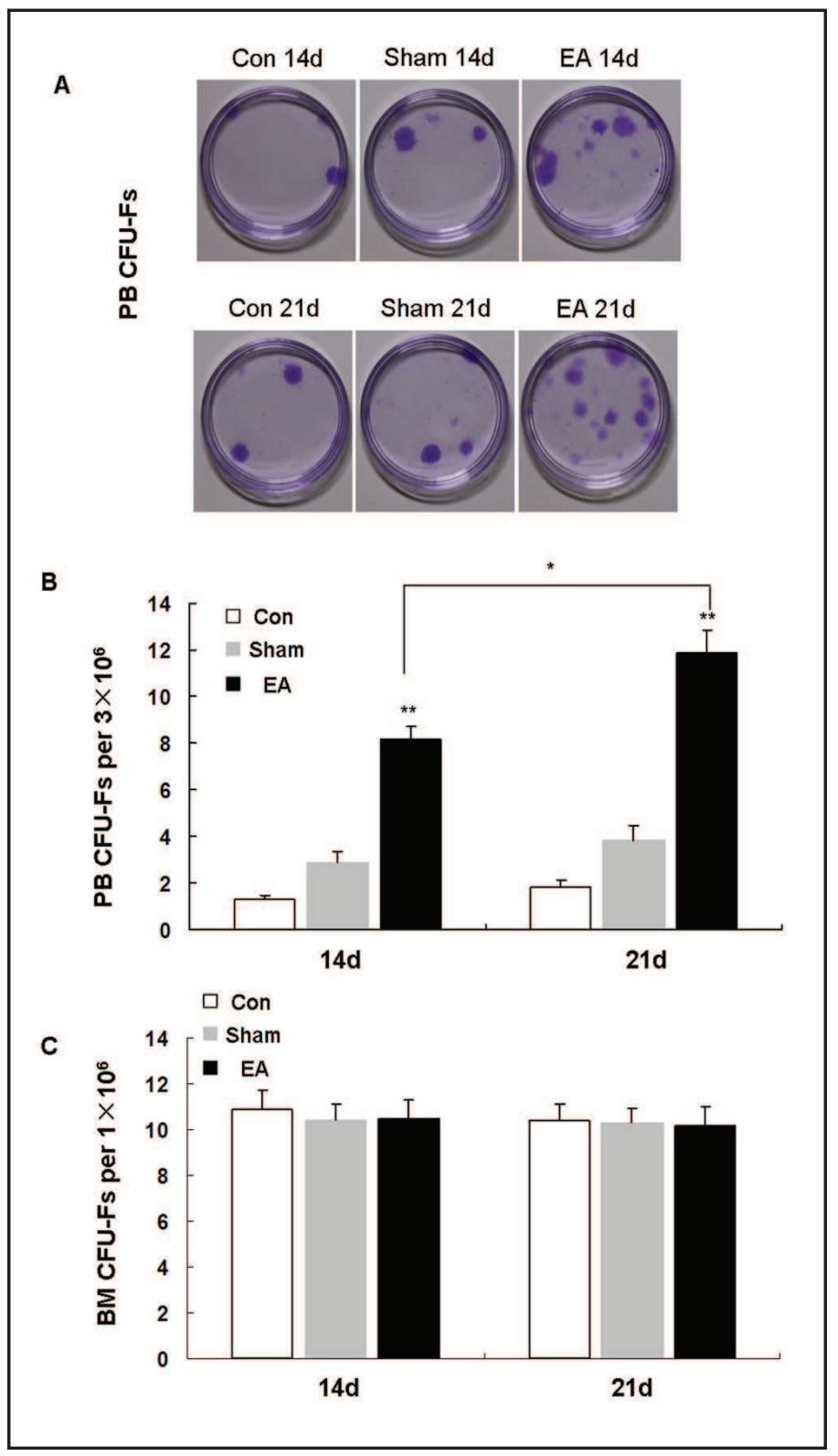

\section{Results}

MSCs were mobilized into peripheral blood by EA treatment

The CFU-F assay is a standard, widely used method to quantify the number of MSCs in circulation. To investigate the effect of EA on MSC mobilization, CFU-F assays were performed on PB and BM samples from each group. As each colony (colony-forming unitfibroblast, CFU-F) originates from a single progenitor cell, the number of CFU-Fs represents the frequency of MSCs. As shown in Fig. 2A, more colonies were observed in the PB of the EA14d group compared to the sham and control groups. Surprisingly, the number of PB CFUFs increased further in EA21d rats. Quantitative analysis indicated that a dramatic increase in CFU-F frequency was observed in the PB of rats subjected to EA treatment for 14 days $(P<0.01)$ (Fig. 2B). Mean values $( \pm$ SEM) were $1.30 \pm 0.15$ and $8.20 \pm 0.53$ CFU-Fs per $3 \times$ $10^{6}$ MNCs in control and EA14d samples, respectively. Intriguingly, the number of CFU-Fs was increased further in the EA21d group (11.9 $\pm 0.91 v s .8 .20 \pm 0.53, P<0.05)$ (Fig. 2B). These data indicate that EA promotes endogenous MSC mobilization into peripheral blood. 


\section{Cellular Physiology

A
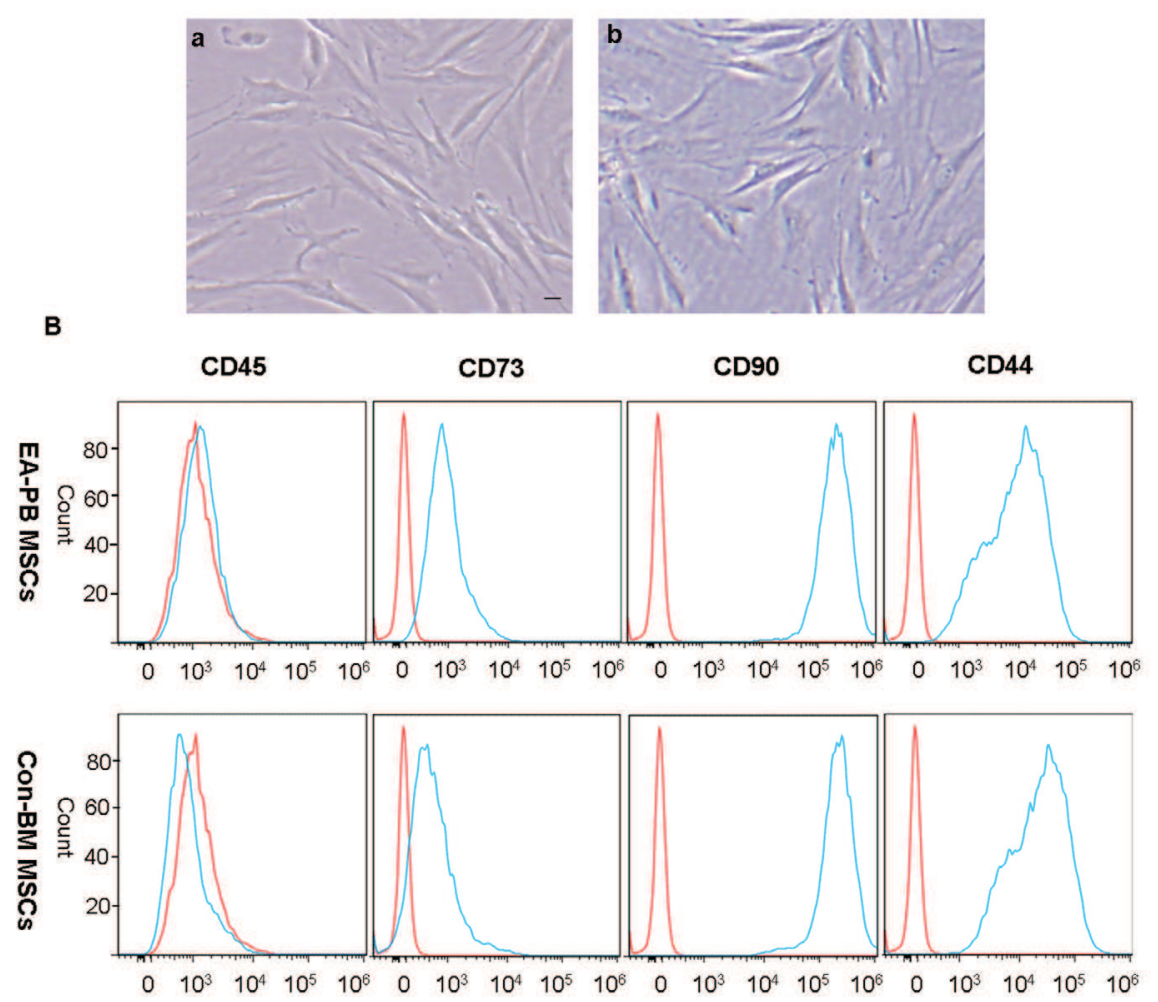

Fig. 3. Morphology and immunophenotype of MSCs. Cells from mobilized PB of EA 14d (EA-PB) were cultured in parallel with MSCs from the bone marrow of Con 14d rats (Con-BM). (A) Morphology of Passage 3 MSCs from EA-PB (a) and Con-BM (b) was observed by phase-contrast microscopy. Scale bar = 25 mm. (B) Immunophenotype. Membrane antigen expression of EA-PB MSCs and Con-BM MSCs was determined by flow cytometry. Fluorescence intensity histograms for specific antibodies (Abs) to each membrane antigen are indicated by red lines. Isotype control Abs served as negative controls (blue lines). Experiments were performed in triplicate.

Interestingly, no significant differences in BM CFU-Fs were observed among the groups $(P$ $>0.05$ ), with mean frequencies of between $10.20 \pm 0.73$ and $10.90 \pm 0.82$ CFU-Fs per $10^{6}$ cells (Fig. 2C), suggesting that EA either induces MSC egress from BM into circulating blood without significantly influencing the BM pool, or mobilizes MSCs from other non-BM sources such as adipose tissue $[15,25]$.

The morphology and immunophenotype of MSCs derived from EA-mobilized PB

MSCs from EA-mobilized PB were cultured in parallel with cells from BM. The morphology of CFU-Fs derived from EA-mobilized PB (Fig. 3Aa) was similar to that from BM (Fig. 3Ab).

To examine their immunophenotype, the mobilized cells from the PB of rats subjected to EA $14 \mathrm{~d}$ treatment were cultured. The cell surface antigen expression of adherent cells (Passage 3) was detected by flow cytometry. As shown in Fig. 3B, mobilized cells were positive for CD90 (Thy-1) and CD44 (homing-associated cell adhesion molecule), moderately expressed CD73 (cluster of differentiation 73), but were negative for CD45 (leukocyte common antigen). The cell-surface immunophenotype of mobilized PB MSCs was therefore comparable to that of MSCs derived from bone marrow of control rats. 


\section{Cellular Physiology Cell Physiol Biochem 2016;38:1605-1617 \begin{tabular}{l|l|l|l}
\cline { 2 - 3 } DOI: 10.1159/000443101 & () 2016 The Author(s). Published by S. Karger AG, Basel \\
www Biochemistry
\end{tabular} and Biochemistry Published online: April 18, 2016 www.karger.com/cpb}

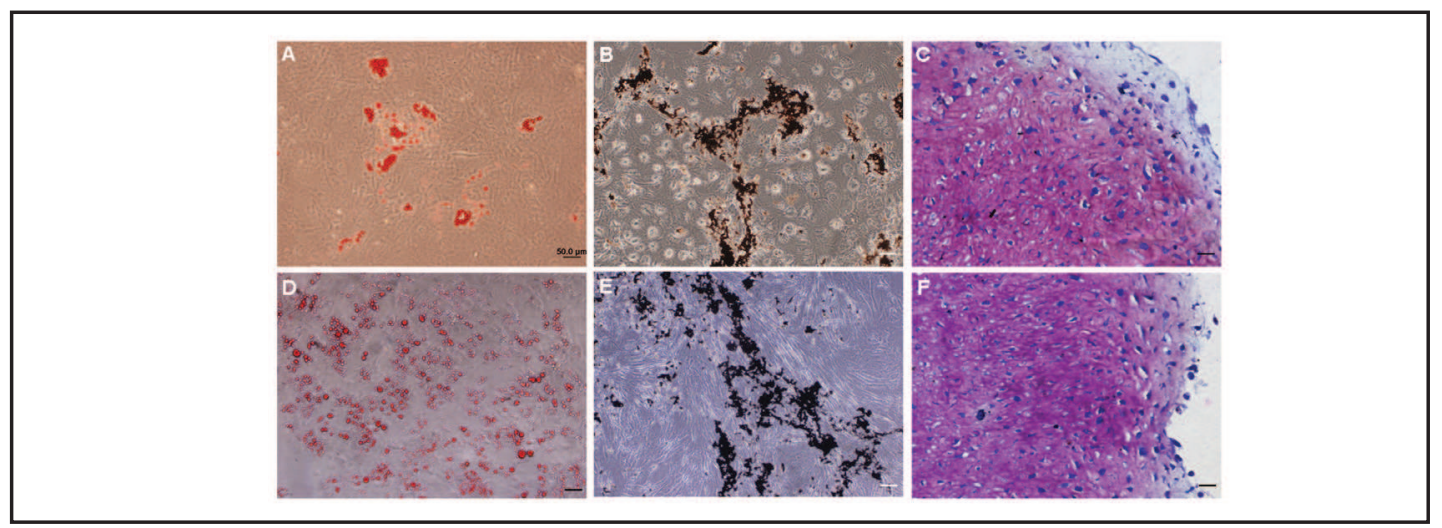

Fig. 4. Tri-lineage differentiation capacities. Cells from the mobilized PB of EA 14d (EA-PB) rats were cultured in parallel with MSCs from the bone marrow of Con 14d rats (Con-BM). EA-PB and Con-BM-derived MSCs were cultured in adipogenic, osteogenic, or chondrogenic differentiation media. Adipogenic induction of EA-PB MSCs (A) and Con-BM MSCs (D) stained with Oil Red O. Scale bar $=50 \mu \mathrm{m}$. Osteogenic induction of EA-PB MSCs (B) and Con-BM MSCs (E) labeled with von Kossa stain. Scale bar $=100 \mu \mathrm{m}$. Chondrogenic induction of EA-PB MSCs (C) and Con-BM MSCs (F) stained with Toluidine Blue. Scale bar = $25 \mu \mathrm{m}$.

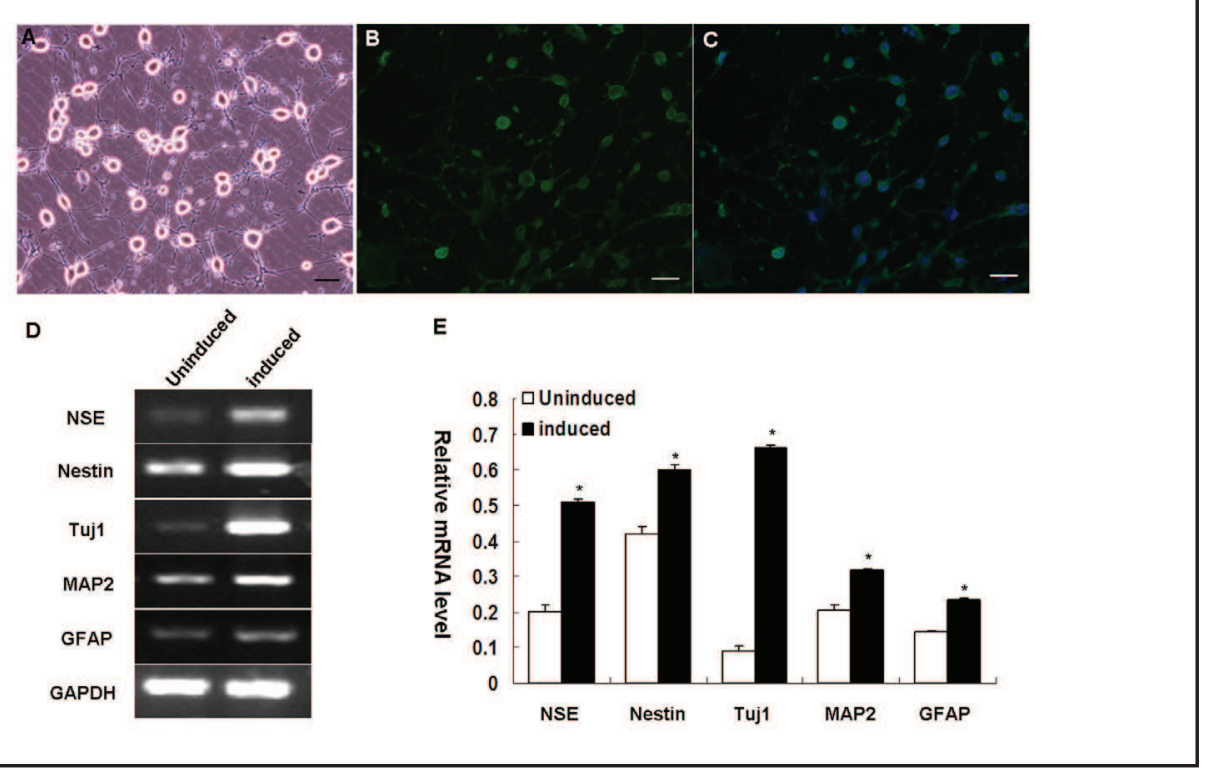

Fig. 5. Neuronal differentiation potentials of MSCs derived from EA-mobilized PB. (A) Morphology of neuron-like cells differentiated from PB-MSCs. (B-C) The expression of nestin on PB-MSCs was detected by immunofluorescence. Nestin was stained with secondary FITC-labeled antibodies, while nuclei were stained with DAPI. (A-C) Scale bar $=50 \mu \mathrm{m}$. (D) RT-PCR analysis demonstrated that the mRNA levels of neuronal markers were increased in neuronal-induced PB-MSCs. GAPDH was used as a control. (E) Quantification of neuronal marker mRNA levels shown in D. The intensity of each gene was normalized to GAPDH, and experiments were repeated three times. ${ }^{*} \mathrm{p}<0.05$ vs. uninduced MSC group.

\section{Multiple differentiation potentials of MSCs derived from EA-mobilized PB}

The differentiation capacities of mobilized PB-derived MSCs were assessed after culture in adipogenic, osteogenic, and chondrogenic induction media for 14 to 21 days. Specific stains were used to detect cytoplasmic neutral lipid vacuoles, mineralized areas, and cartilage glycosaminoglycans. MSCs derived from EA-mobilized PB could differentiate into adipocytes (Fig. 4A), osteoblasts (Fig. 4B), and chondrocytes (Fig. 4C). These results show that PB- 


\section{Cellular Physiology Cell Physiol Biochem 2016;38:1605-1617 \begin{tabular}{ll|l}
\cline { 2 - 3 } DOI: 10.1159/000443101 & (c) 2016 The Author(s). Published by S. Karger AG, Basel \\
\hline
\end{tabular} and Biochemistry Published online: April 18, 2016 www.karger.com/cpb}

A

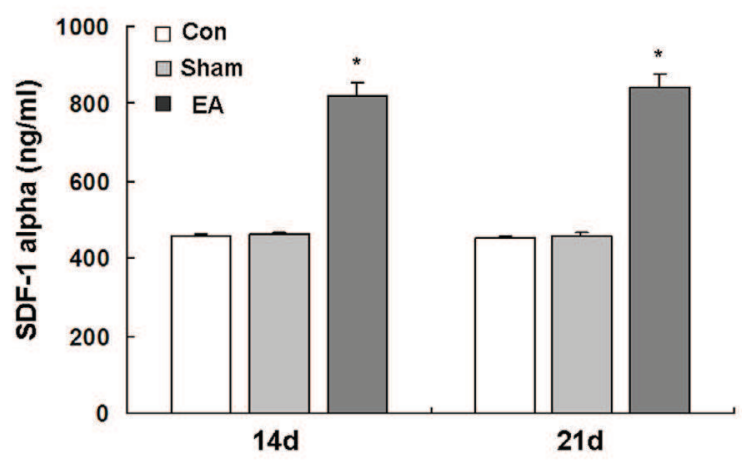

B

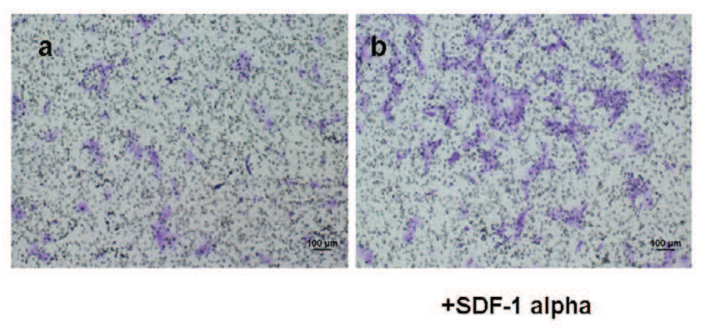

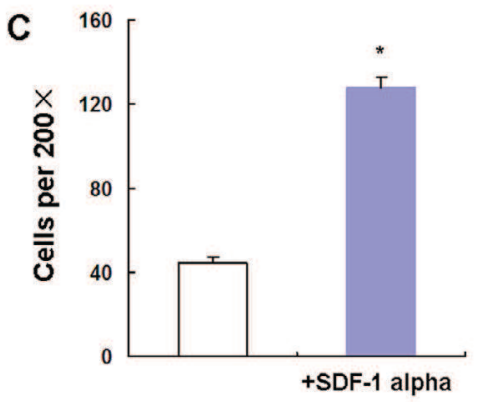

Fig. 6. SDF-1 $\alpha$ increased in the PB of EA groups and promoted the migration of MSCs. (A) Concentrations of SDF- $1 \alpha$ in the Control (Con), Sham EA (sham) and EA-stimulated (EA) groups. *p $<0.05 v$ s. matched control or sham group. (B) The migration of MSCs induced by SDF-1 $\alpha$ was detected using Transwell assays. Migrated MSCs were stained with crystal violet. a., b. Scale bar $=100 \mu \mathrm{m}$. (C) Quantification of Transwell assay results. $* \mathrm{p}<0.05$.

derived MSCs from EA-treated rats display tri-lineage differentiation potential comparable to that of BM-derived MSCs (Fig. 4D-F). Taken together, EA-mobilized, PB-derived adherent cells were demonstrated to be bona fide MSCs on the basis of CFU-Fs, immunophenotype, and tri-lineage differentiation potential.

Neuronal differentiation potential of MSCs derived from EA-mobilized PB

Previous studies have demonstrated that MSCs may be a promising candidate for promoting the recovery of neuronal injury [26]. We therefore studied the neuronal differentiation potential of EA-mobilized PB-derived MSCs. Following induction with bFGF and forskolin, these cells adopted the morphological features typical of neurons, such as refractile cell bodies and long branching processes with growth cone-like terminal structures (Fig. 5A). Induction of the neuronal phenotype resulted in high expression of nestin, a neuronal stem cell marker (Fig. 5B-C). RT-PCR analysis demonstrated that the mRNA levels of neuronal marker genes, including NSE, Nestin, Tuj1, MAP2 and GFAP, were also remarkably increased in neuronal- induced PB MSCs (Fig. 5D-E).

Levels of SDF-1 $\alpha$ were increased in the PB of rats subjected to EA treatment and migration of MSCs was improved in response to SDF-1 $\alpha$

Cytokines may play critical roles in regulating mobilization, trafficking and homing of stem cells. Among these factors, the roles of VEGF and SDF- $1 \alpha$ are well established in the process of MSC mobilization [16]. We therefore determined the levels of these two factors in the PB of each group of animals. Compared to the control groups, the concentration of SDF$1 \alpha$ was remarkably elevated in the PB of rats subjected to EA treatment for 14 days (821.30 $\pm 32.58 v s .457 .24 \pm 4.95 \mathrm{ng} / \mathrm{ml}, p<0.05$ ). The concentration of SDF- $1 \alpha$ was maintained at a steady level in the EA21d group (Fig. 6A). However, there were no differences in PB VEGF levels between EA treated and control groups (data not shown). 


\section{Cellular Physiology Cell Physiol Biochem 2016;38:1605-1617 \\ \begin{tabular}{ll|l} 
and Biochemistry $10.1159 / 000443101$ & $\begin{array}{l}\text { O 2016 The Author(s). Published by S. Karger AG, Basel } \\
\text { www.karger.com/cpb }\end{array}$ \\
\hline
\end{tabular}}

Liu et al.: Electro-Acupuncture Promotes MSC Mobilization into the PB

Mobilization of stem and progenitor cells is a multistage process, with initial release from the BM niche followed by active migration across the BM sinusoidal endothelium. Migration is an important step in this process. We therefore investigated the effect of SDF$1 \alpha$, which was increased in EA-treated rats, on MSC migration using Transwell migration assays. The results showed that MSCs migrated more rapidly in response to SDF- $1 \alpha(127.80$ \pm 4.53 vs. $44.60 \pm 2.38$ cells per $200 \times$ field, Fig. $6 \mathrm{~B}-\mathrm{C}$ ), confirming that SDF- $1 \alpha$ promotes the migration of MSCs.

\section{Discussion}

Following adequate stimulation, stem and progenitor cells may leave their niche and circulate in the PB, a process termed "mobilization" [9]. Strategies to enhance the mobilization of MSCs into the bloodstream are of great therapeutic interest because they would facilitate collection of MSCs from the PB and their subsequent homing to injured tissues. In this study, we found that the number of MSCs increased dramatically in the PB of rats subjected to EA stimulation. To our knowledge, this is the first report that MSCs can be mobilized into the PB by EA.

Although the existence of circulating MSCs has been proven in foetal and neonatal blood [27, 28], attempts to isolate MSCs from adult PB has resulted in both successes [29, $30]$ and failures [31, 32]. Recently, it has become apparent that a small number of MSCs can be mobilized into the PB in response to injury signals $[16,17,33]$ or following appropriate stimuli $[18,19]$. Further evidence suggests that combinations of growth factors with the CXCR4 antagonist AMD3100 effectively induces release of MSCs into the peripheral circulation [34, 35]. However, more work is required before these new mobilization regimes can be introduced into the clinic. Previous studies have reported that EA could promote the survival and homing of transplanted bone marrow MSCs [22]. Our study indicated that EA was a sensitive stimulus for MSC mobilization. Because EA has been used widely in the clinic, our data may provide a novel strategy for enhancing the mobilization of MSCs.

There are numerous studies suggesting that MSCs are stimulated to leave their niche, released into circulation and recruited into damaged tissues under injury conditions $[16,17$, 33]. To rule out lesion-related stem cell mobilization, we therefore used wild-type rats instead of a disease model in this study. In Traditional Chinese Medicine, EA on "Governor Vessel" acupoints is used for the treatment of spinal cord injury (SCI) and has achieved remarkable results [36]. Increasing evidence also suggests that MSCs might be a promising candidate for promoting recovery of neuronal injury [37]. Hence, we chose Jizhong (GV6) and Mingmen (GV4), one pair of "Governor Vessel" acupoints, to investigate the MSC-mobilizing effect of EA. Although our results showed that EA on this pair of acupoints increased the egress of MSCs, the mobilizing effect of EA on other acupoints should be further investigated. Our data indicated that a slight increase in CFU-F frequency was observed in the PB of sham EA rats compared with matched controls, although this result did not achieve statistical significance. These data also suggested that subcutaneous needle insertion might result in a non-specific stimulation promoting MSC migration.

The factors responsible for MSC mobilization by EA remain unknown. Several studies have indicated that EA stimulation in specific frequencies applied to certain body sites can facilitate the release of specific neuropeptides, such as substance P, which acts early in the wound healing process and induces MSC mobilization [38-40]. A recent study has also shown that EA at the sciatic nerve leads to the production of dopamine [41], which regulates mobilization of MSCs during wound angiogenesis [42]. Moreover, cytokines play critical roles in regulating mobilization, trafficking and homing of stem cells. Among these factors, the roles of VEGF and SDF- $1 \alpha$ are well established in the process of MSC mobilization $[19,42]$. In addition, the combination of G-CSF and stem cell factor (SCF) has been shown to enhance MSC mobilization [43]. Intriguingly, several studies have confirmed that the plasma levels of SDF-1 $\alpha$, SCF and VEGF increased significantly after EA stimulation [44-46]. Our 


\section{Cellular Physiology Cell Physiol Biochem 2016;38:1605-1617 \begin{tabular}{l|l|l} 
DOI: 10.1159/000443101 & $\begin{array}{l}\text { @ 2016 The Author(s). Published by S. Karger AG, Basel } \\
\text { www.karger.com/cpb }\end{array}$ \\
\hline
\end{tabular} Liu et al.: Electro-Acupuncture Promotes MSC Mobilization into the PB}

results also confirmed that the level of SDF- $1 \alpha$ was increased in the PB of rats subjected to EA treatment and that MSC migration was improved in response to SDF- $1 \alpha$, suggesting that EA may induce MSC mobilization by modulating the expression of relevant cytokines. Nevertheless, the mechanisms involved in the mobilizing effect of EA may be complex and thus require further study.

EA is beneficial in the treatment of neurological injuries, including stroke [47] and SCI [36]. However, the underlying mechanisms remain unclear. A possible explanation for EA-induced neuronal regeneration could be the mobilization of regenerative stem cells. Increasing evidence has demonstrated that MSC transplantation improves clinical outcomes in models of stroke [48] and SCI [37]. Therefore, MSC mobilization might be a candidate approach for neurological tissue repair. Our results suggested that endogenous MSC mobilization might be one of the mechanisms of EA treatment.

Many studies have demonstrated that bone marrow-derived MSCs can give rise to neuronal cells, both in vitro and in vivo (reviewed in [49]). Transdifferentiation of MSCs into neuronal cells can be obtained by manipulation of culture conditions and biochemical supplements to which the cells are exposed and in which they are maintained. However, there is little evidence supporting the neuronal differentiation potential of PB-derived MSCs. Our results demonstrate that mobilized MSCs isolated from the PB express MSC-specific markers and acquire neuronal-like morphology and neuronal marker expression after induction by bFGF and forskolin.

\section{Conclusion}

Taken together, EA promotes the mobilization of endogenous multipotential MSCs into the PB. Our data provide a promising strategy for MSC mobilization and may help to promote understanding of the underlying mechanisms of EA treatment.

\section{Abbreviations}

MSCs (mesenchymal stem cells); EA (Electro-acupuncture); CFU-F (colony-forming unit fibroblast); VEGF (vascular endothelial growth factor); SDF-1 $\alpha$ (stromal cell-derived factor-1 $\alpha$ ); G-CSF (granulocyte colony-stimulating factor); PB (peripheral blood); MNCs (Mononuclear cells); FBS (foetal bovine serum); bFGF (basic fibroblast growth factor); NSE (neuron-specific enolase); MAP2 (microtubule-associated protein 2); GFAP (glial fibrillary acidic protein); SCI (spinal cord injury); SCF (stem cell factor).

\section{Acknowledgments}

This work was supported by the National Natural Science Foundation of China (81270566, 81500114), Research fund for the Doctoral Program of Higher Education China (20130101120022) and Zhejiang provincial grants (LQ13H080001, 2014KYA069).

\section{Disclosure Statement}

The authors declare that no competing financial interests exist.

\section{References}

1 Pittenger MF, Mackay AM, Beck SC, Jaiswal RK, Douglas R, Mosca JD, Moorman MA, Simonetti DW, Craig S, Marshak DR: Multilineage potential of adult human mesenchymal stem cells. Science 1999;284:143-147.

2 Jiang Y, Jahagirdar BN, Reinhardt RL, Schwartz RE, Keene CD, Ortiz-Gonzalez XR, Reyes M, Lenvik T, Lund T, Blackstad M, Du J, Aldrich S, Lisberg A, Low WC, Largaespada DA, Verfaillie CM: Pluripotency of mesenchymal stem cells derived from adult marrow. Nature 2002;418:41-49.

3 Feng C, Liu H, Yang Y, Huang B, Zhou Y: Growth and differentiation factor-5 contributes to the structural and functional maintenance of the intervertebral disc. Cell Physiol Biochem 2015;35:1-16. 


\section{Cellular Physiology Cell Physiol Biochem 2016;38:1605-1617 \begin{tabular}{l|l|l} 
DOI: 10.1159/000443101 & $\begin{array}{l}\text { C 2016 The Author(s). Published by S. Karger AG, Basel } \\
\text { www.karger.com/cpb }\end{array}$ \\
\hline
\end{tabular}}

Liu et al.: Electro-Acupuncture Promotes MSC Mobilization into the PB

4 Dezawa M, Kanno H, Hoshino M, Cho H, Matsumoto N, Itokazu Y, Tajima N, Yamada H, Sawada H, Ishikawa H, Mimura T, Kitada M, Suzuki Y, Ide C: Specific induction of neuronal cells from bone marrow stromal cells and application for autologous transplantation. J Clin Invest 2004;113:1701-1710.

5 Tohill M, Mantovani C, Wiberg M, Terenghi G: Rat bone marrow mesenchymal stem cells express glial markers and stimulate nerve regeneration. Neurosci Lett 2004;362:200-203.

6 Alhadlaq A, Mao JJ: Mesenchymal stem cells: Isolation and therapeutics. Stem Cells Dev 2004;13:436-448.

7 Bader AM, Brodarac A, Klose K, Bieback K, Choi YH, Kang KS, Kurtz A, Stamm C: Cord blood mesenchymal stromal cell-conditioned medium protects endothelial cells via stat3 signaling. Cell Physiol Biochem 2014;34:646-657.

8 Zhang J, Wu Y, Chen A, Zhao Q: Mesenchymal stem cells promote cardiac muscle repair via enhanced neovascularization. Cell Physiol Biochem 2015;35:1219-1229.

9 Levesque JP, Winkler IG, Larsen SR, Rasko JE: Mobilization of bone marrow-derived progenitors. Handb Exp Pharmacol 2007;180:3-36.

10 Pelus LM: Peripheral blood stem cell mobilization: New regimens, new cells, where do we stand. Curr Opin Hematol 2008;15:285-292.

11 Pitchford SC, Hahnel MJ, Jones CP, Rankin SM: Troubleshooting: Quantification of mobilization of progenitor cell subsets from bone marrow in vivo. J Pharmacol Toxicol Methods 2010;61:113-121.

12 Aicher A, Zeiher AM, Dimmeler S: Mobilizing endothelial progenitor cells. Hypertension 2005;45:321-325.

13 Cashen AF, Link D, Devine S, DiPersio J: Cytokines and stem cell mobilization for autologous and allogeneic transplantation. Curr Hematol Rep 2004;3:406-412.

14 Takano H, Ohtsuka M, Akazawa H, Toko H, Harada M, Hasegawa H, Nagai T, Komuro I: Pleiotropic effects of cytokines on acute myocardial infarction: G-csf as a novel therapy for acute myocardial infarction. Curr Pharm Des 2003;9:1121-1127.

15 He Q, Wan C, Li G: Concise review: Multipotent mesenchymal stromal cells in blood. Stem Cells 2007;25:6977.

16 Mansilla E, Marin GH, Drago H, Sturla F, Salas E, Gardiner C, Bossi S, Lamonega R, Guzman A, Nunez A, Gil MA, Piccinelli G, Ibar R, Soratti C: Bloodstream cells phenotypically identical to human mesenchymal bone marrow stem cells circulate in large amounts under the influence of acute large skin damage: New evidence for their use in regenerative medicine. Transplant Proc 2006;38:967-969.

17 Alm JJ, Koivu HM, Heino TJ, Hentunen TA, Laitinen S, Aro HT: Circulating plastic adherent mesenchymal stem cells in aged hip fracture patients. J Orthop Res 2010;28:1634-1642.

18 Rochefort GY, Delorme B, Lopez A, Herault O, Bonnet P, Charbord P, Eder V, Domenech J: Multipotential mesenchymal stem cells are mobilized into peripheral blood by hypoxia. Stem Cells 2006;24:2202-2208.

19 Liu L, Yu Q Lin J, Lai X, Cao W, Du K, Wang Y, Wu K, Hu Y, Zhang L, Xiao H, Duan Y, Huang H: Hypoxiainducible factor-1alpha is essential for hypoxia-induced mesenchymal stem cell mobilization into the peripheral blood. Stem Cells Dev 2011;20:1961-1971.

20 Moldenhauer S, Burgauner M, Hellweg R, Lun A, Hohenboken M, Dietz E, Kiesewetter H, Salama A, Moldenhauer A: Mobilization of cd133(+)cd34(-) cells in healthy individuals following whole-body acupuncture for spinal cord injuries. J Neurosci Res 2010;88:1645-1650.

21 Chen YY, Zhang W, Chen YL, Chen SJ, Dong H, Zeng YS: Electro-acupuncture improves survival and migration of transplanted neural stem cells in injured spinal cord in rats. Acupunct Electrother Res 2008;33:19-31.

22 Ding Y, Yan Q, Ruan JW, Zhang YQ Li WJ, Zhang YJ, Li Y, Dong H, Zeng YS: Electro-acupuncture promotes survival, differentiation of the bone marrow mesenchymal stem cells as well as functional recovery in the spinal cord-transected rats. BMC Neurosci 2009;10:35.

23 Ho TJ, Chan TM, Ho LI, Lai CY, Lin CH, Macdonald I, Harn HJ, Lin JG, Lin SZ, Chen YH: The possible role of stem cells in acupuncture treatment for neurodegenerative diseases: A literature review of basic studies. Cell Transplant 2014;23:559-566.

24 Liu Z, Ding Y, Zeng YS: A new combined therapeutic strategy of governor vessel electro-acupuncture and adult stem cell transplantation promotes the recovery of injured spinal cord. Curr Med Chem 2011;18:5165-5171.

25 Yang YI, Kim HI, Choi MY, Son SH, Seo MJ, Seo JY, Jang WH, Youn YC, Choi KJ, Cheong SH, Shelby J: Ex vivo organ culture of adipose tissue for in situ mobilization of adipose-derived stem cells and defining the stem cell niche. J Cell Physiol 2010;224:807-816.

26 Jang S, Cho HH, Cho YB, Park JS, Jeong HS: Functional neural differentiation of human adipose tissuederived stem cells using bfgf and forskolin. BMC Cell Biol 2010;11:25. 


\section{Cellular Physiology Cell Physiol Biochem 2016;38:1605-1617 \begin{tabular}{c|l|l} 
DOI: 10.1159/000443101 & $\begin{array}{l}\text { ○ 2016 The Author(s). Published by S. Karger AG, Basel } \\
\text { www.karger.com/cpb }\end{array}$ \\
\hline
\end{tabular}}

Liu et al.: Electro-Acupuncture Promotes MSC Mobilization into the PB

27 Campagnoli C, Roberts IA, Kumar S, Bennett PR, Bellantuono I, Fisk NM: Identification of mesenchymal stem/progenitor cells in human first-trimester fetal blood, liver, and bone marrow. Blood 2001;98:23962402.

28 Lee OK, Kuo TK, Chen WM, Lee KD, Hsieh SL, Chen TH: Isolation of multipotent mesenchymal stem cells from umbilical cord blood. Blood 2004;103:1669-1675.

29 Zvaifler NJ, Marinova-Mutafchieva L, Adams G, Edwards CJ, Moss J, Burger JA, Maini RN: Mesenchymal precursor cells in the blood of normal individuals. Arthritis Res 2000;2:477-488.

30 Kuznetsov SA, Mankani MH, Gronthos S, Satomura K, Bianco P, Robey PG: Circulating skeletal stem cells. J Cell Biol 2001;153:1133-1140.

31 Lazarus HM, Haynesworth SE, Gerson SL, Caplan AI: Human bone marrow-derived mesenchymal (stromal) progenitor cells (mpcs) cannot be recovered from peripheral blood progenitor cell collections. J Hematother 1997;6:447-455.

32 Wexler SA, Donaldson C, Denning-Kendall P, Rice C, Bradley B, Hows JM: Adult bone marrow is a rich source of human mesenchymal 'stem' cells but umbilical cord and mobilized adult blood are not. Br J Haematol 2003;121:368-374.

33 Ramirez M, Lucia A, Gomez-Gallego F, Esteve-Lanao J, Perez-Martinez A, Foster C, Andreu AL, Martin MA, Madero L, Arenas J, Garcia-Castro J: Mobilisation of mesenchymal cells into blood in response to skeletal muscle injury. Br J Sports Med 2006;40:719-722.

34 Pitchford SC, Furze RC, Jones CP, Wengner AM, Rankin SM: Differential mobilization of subsets of progenitor cells from the bone marrow. Cell Stem Cell 2009;4:62-72.

35 Kumar S, Ponnazhagan S: Mobilization of bone marrow mesenchymal stem cells in vivo augments bone healing in a mouse model of segmental bone defect. Bone 2012;50:1012-1018.

36 Dorsher PT, McIntosh PM: Acupuncture's effects in treating the sequelae of acute and chronic spinal cord injuries: A review of allopathic and traditional chinese medicine literature. Evid Based Complement Alternat Med 2011; 428108.

37 Wright KT, El Masri W, Osman A, Chowdhury J, Johnson WE: Concise review: Bone marrow for the treatment of spinal cord injury: Mechanisms and clinical applications. Stem Cells 2011;29:169-178.

38 Hong HS, Lee J, Lee E, Kwon YS, Ahn W, Jiang MH, Kim JC, Son Y: A new role of substance p as an injuryinducible messenger for mobilization of cd29(+) stromal-like cells. Nat Med 2009;15:425-435.

39 Franck J, Brodin E, Fried G: Differential release of endogenous 5-hydroxytryptamine, substance p, and neurokinin a from rat ventral spinal cord in response to electrical stimulation. J Neurochem 1993;61:704711.

40 Bucinskaite V, Theodorsson E, Crumpton K, Stenfors C, Ekblom A, Lundeberg T: Effects of repeated sensory stimulation (electro-acupuncture) and physical exercise (running) on open-field behaviour and concentrations of neuropeptides in the hippocampus in wky and shr rats. Eur J Neurosci 1996;8:382-387.

41 Torres-Rosas R, Yehia G, Pena G, Mishra P, del Rocio Thompson-Bonilla M, Moreno-Eutimio MA, Arriaga-Pizano LA, Isibasi A, Ulloa L: Dopamine mediates vagal modulation of the immune system by electroacupuncture. Nat Med 2014;20:291-295.

42 Shome S, Dasgupta PS, Basu S: Dopamine regulates mobilization of mesenchymal stem cells during wound angiogenesis. PLoS One 2012;7:e31682.

43 To LB, Levesque JP, Herbert KE, Winkler IG, Bendall LJ, Hiwase DK, Antonenas V, Rice AM, Gottlieb D, Mills AK, Rasko JE, Larsen S, Beligaswatte A, Nilsson SK, Cooney JP, Cambareri AC, Lewis ID: Mobilisation strategies for normal and malignant cells. Pathology 2011;43:547-565.

44 Kim JH, Choi KH, Jang YJ, Kim HN, Bae SS, Choi BT, Shin HK: Electroacupuncture preconditioning reduces cerebral ischemic injury via bdnf and sdf-1alpha in mice. BMC Complement Altern Med 2013;13:22.

45 Pan J, Zhang W, Yan J, Chang XR, Zhang H, Chen WS, Shi WY, Pan C: Effects of electroacupuncture of acupoints of pericardium meridian on serum vegf content and cerebral vegf expression in cerebral ischemia rats. Zhen Ci Yan Jiu 2012;37:197-201.

46 Chen Y, Xu J, Liu S, Hou X: Electroacupuncture at st36 increases contraction of the gastric antrum and improves the scf/c-kit pathway in diabetic rats. Am J Chin Med 2013;41:1233-1249.

47 Pei J, Sun L, Chen R, Zhu T, Qian Y, Yuan D: The effect of electro-acupuncture on motor function recovery in patients with acute cerebral infarction: A randomly controlled trial. J Tradit Chin Med 2001;21:270-272.

48 Honmou O, Onodera R, Sasaki M, Waxman SG, Kocsis JD: Mesenchymal stem cells: Therapeutic outlook for stroke. Trends Mol Med 2012;18:292-297.

49 Chen Y, Teng FY, Tang BL: Coaxing bone marrow stromal mesenchymal stem cells towards neuronal differentiation: Progress and uncertainties. Cell Mol Life Sci 2006;63:1649-1657. 